\title{
Constipation is associated with tension type headache in women
}

\author{
Constipação está associada à cefaleia do tipo tensional em mulheres \\ Zeynep Tugba Ozan', Nermin Tanik², Levent Ertugrul Inan ${ }^{2}$
}

\begin{abstract}
Tension-type headaches (TTH) and irritable bowel syndrome (IBS) are comorbid diseases affecting, especially, women. One of the underlying mechanisms for both is autonomic dysfunction in the brain-gut axis. We aimed to evaluate the factors accompanying TTH and their relation to functional gastrointestinal disorders. Methods: Women diagnosed with TTH were questioned about headache pattern and severity, and accompanying factors, as well as being screened for IBS according to the Rome III criteria. The participants were divided into two groups: constipation-dominant IBS (IBS-C) group and "others", with a total of 115 individuals included in the study. Results: Of the 115 patients; $48(41.8 \%)$ of the women had IBS-C criteria while 67 (58.2\%) described mixed-type IBS or diarrhea-dominant IBS. There were no significant differences in terms of mean age $(p=0.290)$, body mass index $(p=0.212)$, visual analog scale $(p=0.965)$, duration of attacks ( $p=0.692)$, and episodic/chronic type ( $p=0.553$ ). Osmophobia was seen in $43.5 \%$; phonophobia in $68.7 \%$, and photophobia in $47.0 \%$ of the patients, and only osmophobia was significantly associated in women in the IBS-C group ( $p=0.001)$. Conclusion: In female patients with TTH, a higher level of constipation was detected. The relationship of these two diseases suggests that they may share common mechanisms. This is the first study showing the relationship of osmophobia with constipation.
\end{abstract}

Keywords: Women; tension-type headache; constipation.

\section{RESUMO}

As cefaléias do tipo tensional (TTH) e a síndrome do intestino irritável (IBS) são comorbidades que afetam especialmente as mulheres. O mecanismo subjacente para ambas é a disfunção autonômica no eixo cérebro-intestino. Nosso objetivo foi avaliar os fatores que acompanham as TTH e sua relação com distúrbios gastrointestinais funcionais (FGID). Métodos: Mulheres com diagnóstico de TTH foram questionadas quanto ao padrão e gravidade da cefaleia, fatores acompanhantes e triadas para IBS de acordo com os critérios de Roma III e foram divididas em dois grupos: grupo com IBS com predominância de constipação (IBS-C) e as demais. Um total de 115 mulheres foram incluídas no estudo. Resultados: Do total de 115 pacientes; 48 (41,8\%) das mulheres tiveram os critérios da IBS-C, enquanto 67 (58,2\%) tiveram IBS do tipo misto ou IBS com predominância de diarreia. Não houve diferenças significativas em termos de idade média $(p=0,290)$, índice de massa corporal (IMC) ( $p=0,212)$, escala visual analógica (VAS) ( $p=0,965)$, duração dos ataques ( $p=0,692)$, e tipo episódico / crônico ( $p=0,553$ ). Osmofobia foi observada em 43,5\% das pacientes; fonofobia em $68,7 \%$ e fotofobia em 47,0\%, e apenas osmofobia foi significativamente associada no grupo de mulheres com predominância de constipação ( $p=0,001)$. Conclusão: Em pacientes do sexo feminino com TTH, encontra-se uma maior constipação. A relação dessas duas doenças sugere que elas podem compartilhar mecanismos comuns. Além disso, este é o primeiro estudo mostrando a relação da osmofobia com a constipação.

Palavras-chave: Mulheres; cefaleia do tipo tensional; constipação intestinal.

The most common complaints of women evaluated in outpatient clinics are headache or abdominal pain. Primary headaches and functional gastrointestinal disorders (FGIDs) are heterogeneous groups of diseases that are extremely prevalent, and can have a huge social and economic burden on society, as well as being the cause a large proportion of job losses ${ }^{1}$. The frequency of irritable bowel syndrome (IBS), a sub-group of FGID, in the community is $15-23 \%$ and the incidence of headache is about $47 \%^{2,3}$. As for comorbidities, the results of many studies have shown that $34-50 \%$ of

${ }^{1}$ Bozok University, Faculty of Medicine, Department of Internal Medicine, Yozgat, Turkey;

${ }^{2}$ Bozok University, Faculty of Medicine, Department of Neurology, Yozgat, Turkey.

Levent Ertugrul Inan (iD) https://orcid.org/0000-0002-2441-0624

Correspondence: Ozan Zeynep Tugba; Bozok University Research and Application; Hospital Internal Medicine Clinic, 66200, Yozgat, Turkey. E-mail adress: drtugba09@gmail.com

Conflict of interest: There is no conflict of interet to declare.

Received 19 June 2018; Received in final form 03 October 2018; Accepted 27 November 2018. 
individuals with IBS symptoms also have headache and, likewise, most patients suffering from headache also have gastrointestinal symptoms ${ }^{4,5}$. In addition, female predominance is reported in the association of headaches and IBS in these studies. The common pathophysiological mechanisms implicated in primary headaches and FGIDs are interactions of visceral hypersensitivity, brain-gut axis, and the neuroimmune and neuroendocrine pathways ${ }^{5,6,7,8}$.

The digestive system and the brain are closely-related parts in the embryo and, consequently, they communicate widely via nerves, and share similar nerve endings and chemicals that direct signals and neurotransmitters. If the signals in the brain-gut axis are distorted or misinterpreted-for example, stress, mood swings or psychological problems - the mobility and secretion of the intestines may be affected, which may contribute to the formation of IBS symptoms. Considered from the opposite side, intestinal sensations can cause pain, mood or behavioral changes by affecting the central brain. In this interaction, the most important neurotransmitter is serotonin, which has an active role in both the digestive system and the nervous system $^{9}$. Serotonin stimulates the secretion in the gastrointestinal pathway, activates afferent nerves and mediates peristalsis developed in response to distension. It has also been reported that plasma serotonin levels seemed to be lower in IBS patients with constipation-dominant symptoms, while the levels were higher in diarrhea-predominant patients ${ }^{10}$. In tension-type headaches (TTH), myofascial trigger points are responsible for the release of pain mediators, and these mediators, with serotonin playing a major role, may also cause excitation and sensitization in peripheral sensory afferents and cause central sensitization ${ }^{11,12}$.

In our study, we examined the factors that also accompany the TTH pain and the interaction of the brain-gut axis in females with TTH. Although these factors accompany migraine, we aimed to determine how often these occur with TTH.

\section{METHODS}

Female patients admitted to the Neurology clinic with a complaint of headache and diagnosed with TTH were included in the study. A single-center, randomized, prospective study was planned with the approval of the Bozok University Faculty of Medicine Ethics Committee (protocol of research: 21.04.2014 / 51). Exclusion criteria were: patients with other primary headaches (including migraine); headache due to drug overuse or secondary causes (headache associated with head and/or neck trauma, cranial or cervical vascular disorders, infection, hypertension, diabetes); rhinitis, sinusitis; major neurological and psychiatric disorders; pregnancy; antidepressant, anxiolytic, antipsychotic, anti-allergic drug users; those with allergic asthma; use of any analgesic (it is known that opioid analgesics may cause constipation and nausea, and various GI symptoms are common as sideeffects of non-steroidal anti-inflammatory drugs).

Initially, 157 women were included in the study. Of these, three were excluded because of pregnancy, 16 for mixed-type headache (to comply with migraine and TTH criteria), three for hypertension, two for diabetes, eight for allergic asthma and 10 for use of an analgesic drug. As there have been many studies on migraine patients and FGIDs in the literature, only women with TTH were included in the study. Demographic, clinical and laboratory data were recorded for the remaining 115 patients included in the study.

Patients were questioned by the same neurologist for headache, either episodic TTH (at least 10 episodes, day but less than 15 days per month for at least three months), or chronic TTH ( $\geq 15$ days per month on average for more than three months). The International Classification of Headache Disorders (2nd and 3rd Editions, beta version) was used for the evaluation of attacks ${ }^{13}$.

The visual analogue scale is a pain intensity measurement scale with proven reliability. Individuals were told that they could evaluate their pain from 0 to 10 , on a $10 \mathrm{~cm}$ line. If the person has no pain it is evaluated at the 0 point (the leftmost point), for the most severe pain it is considered to be 10 points (the rightmost point). The value found on the $10 \mathrm{~cm}$ chart was measured with a ruler and recorded as the severity of the pain ${ }^{14}$. Also, questions were asked about photophobia, phonophobia and osmophobia. The women were then re-examined by an internal medicine specialist. The Rome III criteria were used for the diagnosis of constipation-dominant IBS (IBS-C). The diagnostic criterion (fulfilled for the previous three months with symptom onset at least six months prior to diagnosis) was: recurrent abdominal pain or discomfort at least three days/month in the last three months associated with two or more of the following: 1. Improvement with defecation; 2 . Onset associated with a change in frequency of stool; 3. Onset associated with a change in form (appearance) of stool. "Discomfort" meant an uncomfortable sensation not described as pain. In pathophysiology research and clinical trials, a pain/discomfort frequency of at least two days a week during screening evaluation is recommended for participant eligibility ${ }^{15}$. The study participants were divided into two groups: the IBS-C group, and the others (mixed-type IBS or diarrhea-dominant IBS).

\section{Statistics}

The Statistical Package for the Social Sciences version 16 (SPSS Inc., Chicago, IL, USA) was performed for statistical analysis. The independent sample t-test was used to compare differences between continuous variables, and Chi-square $\left(\chi^{2}\right)$ analysis used to identify differences between categorical variables. P-values $<0.05$ were considered to indicate statistical significance. 
Table 1. Demographic and clinical data of female patients with tension type headache (TTH).

\begin{tabular}{lccc}
\hline Variables & IBS-C group $(\mathrm{n}=48)$ & Without constipation $(\mathrm{n}=67)$ & $\mathrm{p}$-value \\
\hline Age (years) & $40.81 \pm 12.08$ & $44.22 \pm 14.54$ & 0.290 \\
Body mass index $\left(\mathrm{kg} / \mathrm{m}^{2}\right)$ & $30.32 \pm 6.78$ & $28.87 \pm 5.49$ & 0.212 \\
Visual analogue scale & $4.77 \pm 1.93$ & $4.25 \pm 1.95$ & 0.965 \\
Duration of attacks (hours) & $12.91 \pm 14.36$ & $12.81 \pm 13.02$ & 0.692 \\
Episodic & $34(29.5 \%)$ & $47(40.9 \%)$ & 0.553 \\
Chronic & $14(12.3 \%)$ & $20(17.3 \%)$ & \\
\hline
\end{tabular}

IBS-C: constipation-dominant IBS

Table 2. Differences between the two groups in terms of photophobia, phonophobia and osmophobia.

\begin{tabular}{|c|c|c|c|c|}
\hline Variables & Without constipation & IBS-C group & Total & $\mathrm{p}$-value \\
\hline Photophobia + & $29(53.7 \%)$ & $25(46.3 \%)$ & $54(100 \%)$ & \multirow{2}{*}{0.449} \\
\hline Photophobia - & $38(62.3 \%)$ & $23(37.7 \%)$ & $61(100 \%)$ & \\
\hline Phonophobia + & $42(53.2 \%)$ & $37(46.8 \%)$ & $79(100 \%)$ & \multirow{2}{*}{0.109} \\
\hline Phonophobia - & $25(69.4 \%)$ & $11(30.6 \%)$ & $36(100 \%)$ & \\
\hline Osmophobia + & $19(38.0 \%)$ & $31(62 \%)$ & $50(100 \%)$ & \multirow{2}{*}{0.001} \\
\hline Osmophobia - & $46(70.8 \%)$ & $19(29.2 \%)$ & $65(100 \%)$ & \\
\hline
\end{tabular}

\section{RESULTS}

A total of 115 TTH female patients were enrolled in the study; 48 (41.8\%) of the women complained of constipation (IBS-C). In the IBS-C group, the mean age was $40.81( \pm 12.08)$ years and was $44.22( \pm 14.54)$ years in the other group. In terms of mean age and body mass index, there was no statistical difference between the two groups ( $p=0.290,0.212$, respectively) (Table 1). In the evaluation of the visual analogue scale scores of females with TTH, $34.1 \%$ had mild, $50.7 \%$ had moderate, $13 \%$ had severe and $2.2 \%$ had very severe pain. In terms of duration of pain, $63.8 \%$ described short-term pain ( $<12$ hours), $30.4 \%$ had between $12-24$ hours, and 5.8\% had long-term pain (> 24 hours). Of the women with TTH, 70.4\% described episodic TTH, and $29.6 \%$ described chronic TTH. In terms of the visual analogue scale and duration of attacks and episodic/ chronic type, there were no significant differences between the two groups ( $\mathrm{p}=0.965,0.692,0.553$, respectively) (Table 1 ).

When the accompanying factors were examined; osmophobia was described in $43.5 \%$ of patients, phonophobia in $68.7 \%$, and photophobia in $47.0 \%$. Again, no significant differences were detected between the two groups in terms of photophobia and phonophobia $(\mathrm{p}=0.449,0.109$, respectively), but osmophobia was significantly associated with IBS-C $(p=0.001)$ (Table 2).

\section{DISCUSSION}

Approximately half of all IBS patients are reported to have headache complaints. Other common comorbid conditions in IBS patients are known to be fibromyalgia, generalized anxiety disorder, chronic fatigue syndrome or panic disorder. The relationship to stress and the pathogenesis of functional disorders is not yet clear, which seriously challenges the quality of life of the patient, as well as the clinician, for diagnosis and treatment. The underlying pathology of all these diseases is thought to be the visceral hypersensitivity ${ }^{16,17}$. In the case of hypersensitivity, silent receptors that normally should not work are continuously active and even normal stimuli can be felt in the form of pain, or painful stimuli may appear exaggerated. In this context, the brain is confused by exaggerated and contradictory orders parallel to the excessive sensitivity.

The neurotransmitter serotonin, mitochondrial dysfunction (that leads to cellular energy deficits and contributes to autonomic nervous system dysfunction), and psychogenic problems are thought to be the other common mechanisms ${ }^{18,19,20}$. Recent research has revealed that bidirectional brain-gut interactions are involved in regulating gut functions in both healthy and diseased individuals. The role of the central nervous system in modulating the various functions of the gastrointestinal tract is motility, secretion, blood flow, and response to gut-related immune function in the event of a psychological or physical stress. Headache and constipation seem to be manifestations of such two-way brain-intestinal interactions.

In the Head-HUNT Study questionnaire completed by 43,782 individuals, a higher prevalence of headache was found to be correlated with more reflux, diarrhea, constipation (OR 2.1, 95\% CI 1.9 - 2.4) and nausea compared with those without headache; as well gastrointestinal complaints were underestimated in both groups ${ }^{4}$. In another study conducted 
in Korea, $25 \%$ of the patients with primary headache also had complaints of constipation. After being treated for constipation, both the headache and constipation improved. Also, patients with TTH were found more likely to be in the constipation group $(p=0.006)^{21}$. In our study, $41.8 \%$ of TTH females complained of constipation.

Most of the patients with primary headaches experience sensory hyperexcitability manifested as photophobia, phonophobia and osmophobia. In studies with TTH patients, while the frequency of phonophobia was $11-56 \%$, the frequency of photophobia was found to be between $12-60 \%$. In addition, the rate of photophobia was found to be $68 \%$ and the rate of phonophobia was $61 \%$ in the painless period ${ }^{22}$. Similarly, photophobia (47\%) and phonophobia (68\%) rates were higher in our study. There may be two reasons why these rates were high. Firstly, photophobia and/or phonophobia may not be adequately assessed in patients with suspected tension headaches. Secondly, our study was conducted with female patients only. Studies have shown that the odor sensitivity of osmophobia may be higher in women ${ }^{23,24}$. Like osmophobia, the sound sensitivity of phonophobia and the light sensitivity of photophobia can be seen more often in women.

For the first time in the literature, our study found osmophobia correlated with constipation in female patients with TTH. This result may be linked to the neurotransmitter serotonin and hyperexcitability, as headache, osmophobia and IBS-C are thought to have a similar pathogenesis. Osmophobia is defined as an intolerance to odors and is known to be associated with primary headaches. Osmophobia is one of the precipitating factors in individuals with TTH, along with nausea, vomiting, photophobia, phonophobia, and dizziness ${ }^{25,26}$. The exact mechanism for osmophobia is not known. In the attack period of headache in individuals, the sense of smell is different, which is related to the neuronal interaction between the olfactory and trigeminal nociceptive system, and this has been suggested to be caused by central sensitization ${ }^{27,28}$. In mice it has been noticed that, if constantly given smell stimuli, hyperexcitability and anxiety develop as a result of overstimulation of the olfactory system $^{29,30}$. Similarly, in studies carried out on normal individuals, increased sympathetic activity was detected as a result of the inhalation of fragrance ${ }^{31}$. In addition, after sertraline therapy, osmophobia was shown to improve due to an increase of serotonin levels in the circulation ${ }^{32}$.

In the literature there are many studies showing that osmophobia is very specific for the diagnosis of migraine ${ }^{33,34}$. As well, some studies emphasize that osmophobia is a specific, but not very sensitive, symptom in differentiating migraine from other primary headaches ${ }^{35}$. In a study including 300 patients, 199 of whom were women, osmophobia was reported in $84 \%$ of patients with migrainous headache with aura, in $74 \%$ of migrainous patients without aura, and in $43.3 \%$ of those with episodic $\mathrm{TTH}^{23}$. In our study, osmophobia was found in $43.5 \%$ of the TTH patients.

This study has several strengths, including neurologist confirmation of the TTH diagnosis and the use of a standardized questionnaire for FGID symptoms. However, the study also had several limitations. Although the Rome III criteria was used for the characterization of FGID symptoms, we could not differentiate whether gastrointestinal symptoms were functional or organic, as most of the patients did not undergo endoscopy. The FGID remained primarily a clinical diagnosis. Also, in primary headaches, there is a need for greater sampling to assess the association of pain-triggering factors with functional gastrointestinal disorders.

In conclusion, we believe that new studies should be undertaken to clarify the pathophysiologic mechanisms for comorbid diseases. If the pathophysiology is known, it would be extremely useful to the physician in both the diagnosis and treatment phases. If left untreated, these diseases can become a vicious cycle, making the situation more complex for patients and physicians. If it can be predicted that IBS triggers headaches, or that headache triggers IBS, then more accurate treatment can be given, thus improving the satisfaction of both the physician and the patient.

\section{References}

1. Steiner TJ, Birbeck GL, Jensen RH, Katsarava Z, Stovner LJ, Martelletti P. Headache disorders are third cause of disability worldwide. J Headache Pain. 2015;16(1):58. https://doi.org/10.1186/s10194-015-0544-2

2. Breckan RK, Asfeldt AM, Straume B, Florholmen J, Paulssen EJ. Prevalence, comorbidity, and risk factors for functional bowel symptoms: a population-based survey in Northern Norway. Scand J Gastroenterol. 2012 Nov;47(11):1274-82. https://doi.org/10.3109/00365521.2012.688215

3. Minocha A, Johnson WD, Abell TL, Wigington WC. Prevalence, sociodemography, and quality of life of older versus younger patients with irritable bowel syndrome: a population-based study. Dig Dis Sci. 2006 Mar;51(3):446-53. https://doi.org/10.1007/s10620-006-3153-8

4. Aamodt AH, Stovner LJ, Hagen K, Zwart JA. Comorbidity of headache and gastrointestinal complaints. The
Head-HUNT Study. Cephalalgia. 2008 Feb;28(2):144-51. https://doi.org/10.1111/j.1468-2982.2007.01486.x

5. Barbara G, De Giorgio R, Stanghellini V, Cremon C, Salvioli B, Corinaldesi R. New pathophysiological mechanisms in irritable bowel syndrome. Aliment Pharmacol Ther. 2004 Jul;20(s2 Suppl 2):1-9. https://doi.org/10.1111/j.1365-2036.2004.02036.x

6. Whitehead WE, Palsson O, Jones KR. Systematic review of the comorbidity of irritable bowel syndrome with other disorders: what are the causes and implications? Gastroenterology. 2002 Apr;122(4):1140-56. https://doi.org/10.1053/gast.2002.32392

7. Lackner JM, Ma CX, Keefer L, Brenner DM, Gudleski GD, Satchidanand N, et al. Type, rather than number, of mental and physical comorbidities increases the severity of symptoms in patients with irritable bowel syndrome. Clin Gastroenterol Hepatol. 2013 Sep;11(9):1147-57. https://doi.org/10.1016/j.cgh.2013.03.011 
8. Riedl A, Schmidtmann M, Stengel A, Goebel M, Wisser AS, Klapp BF, et al. Somatic comorbidities of irritable bowel syndrome: a systematic analysis. J Psychosom Res. 2008 Jun;64(6):573-82. https://doi.org/10.1016/j.jpsychores.2008.02.021

9. Tietjen GE, Herial NA, Hardgrove J, Utley C, White L. Migraine comorbidity constellations. Headache. 2007 Jun;47(6):857-65. https://doi.org/10.1111/j.1526-4610.2007.00814.x

10. Coleman NS, Foley S, Dunlop SP, Wheatcroft J, Blackshaw E, Perkins $A C$, et al. Abnormalities of serotonin metabolism and their relation to symptoms in untreated celiac disease. Clin Gastroenterol Hepatol. 2006 Jul;4(7):874-81. https://doi.org/10.1016/j.cgh.2006.04.017

11. Bendtsen L, Jensen R. Tension-type headache: the most common, but also the most neglected, headache disorder. Curr Opin Neurol. 2006 Jun;19(3):305-9. https://doi.org/10.1097/01.wco.0000227043.00824.a9

12. Shah JP, Phillips TM, Danoff JV, Gerber LH. An in vivo microanalytical technique for measuring the local biochemical milieu of human skeletal muscle. J Appl Physiol (1985). 2005 Nov;99(5):1977-84. https://doi.org/10.1152/japplphysiol.00419.2005

13. The International Classification of headache disorders, 3 rd edition (beta version). .Cephalalgia, 2013. 33(9):629-808. https://doi.org/10.1177/0333102413485658

14. Melzack R, Bélanger E. Labour pain: correlations with menstrual pain and acute low-back pain before and during pregnancy. Pain. 1989 Feb;36(2):225-9. https://doi.org/10.1016/0304-3959(89)90027-4

15. Longstreth GF, Thompson WG, Chey WD, Houghton LA, Mearin F, Spiller RC. Functional bowel disorders. Gastroenterology. 2006 Apr;130(5):1480-91. https://doi.org/10.1053/j.gastro.2005.11.061

16. Chang FY, Lu CL. Irritable bowel syndrome and migraine: bystanders or partners? J Neurogastroenterol Motil. 2013 Jul;19(3):301-11. https://doi.org/10.5056/jnm.2013.19.3.301

17. Cole JA, Rothman KJ, Cabral HJ, Zhang Y, Farraye FA. Migraine, fibromyalgia, and depression among people with IBS: a prevalence study. BMC Gastroenterol. 2006 Sep;6(1):26. https://doi.org/10.1186/1471-230X-6-26

18. Ferrari MD, OdinkJ, Tapparelli C, Van Kempen GM, Pennings EJ, Bruyn GW. Serotonin metabolism in migraine. Neurology. 1989 Sep;39(9):1239-42. https://doi.org/10.1212/WNL.39.9.1239

19. Keszthelyi D, Troost FJ, Masclee AA. Irritable bowel syndrome: methods, mechanisms, and pathophysiology. Methods to assess visceral hypersensitivity in irritable bowel syndrome. Am J Physiol Gastrointest Liver Physiol. 2012 Jul;303(2):G141-54. https://doi.org/10.1152/ajpgi.00060.2012

20. Burnett BB, Gardner A, Boles RG. Mitochondrial inheritance in depression, dysmotility and migraine? J Affect Disord. 2005 Sep;88(1):109-16. https://doi.org/10.1016/j.jad.2005.05.009

21. Park MN, Choi MG, You SJ. The relationship between primary headache and constipation in children and adolescents. Korean J Pediatr. 2015 Feb;58(2):60-3. https://doi.org/10.3345/kjp.2015.58.2.60

22. Vanagaite Vingen J, Stovner LJ. Photophobia and phonophobia in tension-type and cervicogenic headache. Cephalalgia. 1998 Jul-Aug;18(6):313-8. https://doi.org/10.1046/j.1468-2982.1998.1806313.x

23. Chitsaz A, Ghorbani A, Dashti M, Khosravi M, Kianmehr M. The Prevalence of Osmophobia in Migranous and Episodic Tension Type Headaches. Adv Biomed Res. 2017 Apr;6(1):44. https://doi.org/10.4103/2277-9175.204587

24. Kelman L. The place of osmophobia and taste abnormalities in migraine classification: a tertiary care study of 1237 patients. Cephalalgia. 2004 Nov;24(11):940-6. https://doi.org/10.1111/j.1468-2982.2004.00766.x

25. Saisu A, Tatsumoto M, Hoshiyama E, Aiba S, Hirata K. Evaluation of olfaction in patients with migraine using an odour stick identification test. Cephalalgia. 2011 Jul;31(9):1023-8. https://doi.org/10.1177/0333102411410612

26. Olesen J. International Classification of Headache Disorders, Second Edition (ICHD-2): current status and future revisions. Cephalalgia. 2006 Dec;26(12):1409-10. https://doi.org/10.1111/j.1468-2982.2006.01214.x

27. Stankewitz A, May A. Increased limbic and brainstem activity during migraine attacks following olfactory stimulation. Neurology. 2011 Aug;77(5):476-82. https://doi.org/10.1212/WNL.0b013e318227e4a8

28. Lovati C, Giani L, Castoldi D, Mariotti D’Alessandro C, DeAngeli F, Capiluppi E, et al. Osmophobia in allodynic migraineurs: cause or consequence of central sensitization? Neurol Sci. 2015 May;36(S1 Suppl 1):145-7. https://doi.org/10.1007/s10072-015-2141-1

29. Glinka ME, Samuels BA, Diodato A, Teillon J, Feng Mei D, Shykind BM, et al. Olfactory deficits cause anxiety-like behaviors in mice. J Neurosci. 2012 May;32(19):6718-25. https://doi.org/10.1523/JNEUROSCI.4287-11.2012

30. Martin PR, Todd J, Reece J. Effects of noise and a stressor on head pain. Headache. 2005 Nov-Dec;45(10):1353-64. https://doi.org/10.1111/j.1526-4610.2005.00268.x

31. Haze S, Sakai K, Gozu Y. Effects of fragrance inhalation on sympathetic activity in normal adults. Jpn J Pharmacol. 2002 Nov;90(3):247-53. https://doi.org/10.1254/jjp.90.247

32. Kuo YH, Chang Y, Chen HC, Liao SC. Sertraline alleviated osmophobia caused by partial hypopituitarism with isolated ACTH deficiency. Gen Hosp Psychiatry. 2013 Sep.-Oct;35(5):574.e9-10. https://doi.org/10.1016/j.genhosppsych.2012.07.008

33. Welch KM. Contemporary concepts of migraine pathogenesis. Neurology. 2003 Oct;61 (8 Suppl 4):S2-8. https://doi.org/10.1212/WNL.61.8_suppl_4.S2

34. Zanchin G, Dainese F, Trucco M, Mainardi F, Mampreso E, Maggioni F. Osmophobia in migraine and tensiontype headache and its clinical features in patients with migraine. Cephalalgia. 2007 Sep;27(9):1061-8. https://doi.org/10.1111/j.1468-2982.2007.01421.x

35. Corletto E, Dal Zotto L, Resos A, Tripoli E, Zanchin G, Bulfoni $\mathrm{C}$, et al. Osmophobia in juvenile primary headaches. Cephalalgia. 2008 Aug;28(8):825-31. https://doi.org/10.1111/j.1468-2982.2008.01589.x 